(C) The Authors 2015. This is an Open Access article, distributed under the terms of the Creative Commons Attribution licence (http:// creativecommons.org/licenses/by/3.0/), which permits unrestricted re-use, distribution, and reproduction in any medium, provided the original work is properly cited.

\title{
Postprandial glycaemic response: how is it influenced by characteristics of cereal products?
}

\author{
Alexandra Meynier ${ }^{1 *}$, Aurélie Goux ${ }^{1}$, Fiona Atkinson ${ }^{2}$, Olivier Brack ${ }^{3}$ and Sophie Vinoy ${ }^{1}$ \\ ${ }^{1}$ Nutrition Department, Mondelez International RED, 6 Rue René Razel - Bâtiment K, 91400 Saclay, France \\ ${ }^{2}$ Human Nutrition Unit, School of Molecular Bioscience, University of Sydney, Sydney, NSW 2006, Australia \\ ${ }^{3}$ Statistique Industrielle KHI2 Consulting (KSIC), Esches, France \\ (Submitted 30 June 2014 - Final revision received 30 January 2015 - Accepted 25 March 2015 - First published online 22 May 2015)
}

\section{Abstract}

Cereal products exhibit a wide range of glycaemic indexes (GI), but the interaction of their different nutrients and starch digestibility on blood glucose response is not well known. The objective of this analysis was to evaluate how cereal product characteristics can contribute to GI and insulinaemic index and to the parameters describing glycaemic or insulinaemic responses (incremental AUC, maximum concentration and $\Delta_{\text {peak }}$ ). Moreover, interactions between the different cereal products characteristics and glycaemic response parameters were assessed for the first time. Relationships between the cereal products characteristics and the glycaemic response were analysed by partial least square regressions, followed by modelling. A database including 190 cereal products tested by the usual GI methodology was used. The model on glycaemic responses showed that slowly digestible starch (SDS), rapidly digestible starch (RDS) and fat and fibres, and several interactions involving them, significantly explain GI by $53 \%$ and $\Delta_{\text {peak }}$ of glycaemia by $60 \%$. Fat and fibres had important contributions to glycaemic response at low and medium SDS contents in cereal products, but this effect disappears at high SDS levels. We showed also for the first time that glycaemic response parameters are dependent on interactions between starch digestibility (interaction between SDS and RDS) and nutritional composition (interaction between fat and fibres) of the cereal products. We also demonstrated the non-linear effect of fat and fibres (significant effect of their quadratic terms). Hence, optimising both the formula and the manufacturing process of cereal products can improve glucose metabolism, which is recognised as strongly influential on human health.

\section{Key words: Cereal product: Starch digestibility: Glucose metabolism: Insulin}

Postprandial glycaemia has been implicated in the development of chronic metabolic diseases such as obesity, type 2 diabetes mellitus and $\mathrm{CVD}^{(1)}$. Both the amount and type of carbohydrates (CHO) consumed contribute to glycaemia and insulinaemia $^{(2)}$. In 1981, the concept of glycaemic index (GI) was introduced by Jenkins et al. ${ }^{(3)}$ to rank different foods according to their glycaemic response. Moreover, low GI diets have been shown to improve glycaemic control ${ }^{(4)}$ and insulin sensitivity ${ }^{(5,6)}$ in diabetic patients. They are also independently associated with reduced risk of chronic diseases ${ }^{(7)}$.

Starch is one of the most important glycaemic CHO in cereal products. Among the various classes of processed starchy foods, wheat-based cereal products exhibit a very wide range in $\mathrm{GI}^{(8,9)}$. Intrinsic properties of starch (gelatinisation, amylopectin: amylose ratio, etc.) as well as the nutritional composition of food products influence the rate of starch digestion ${ }^{(10-12)}$.
The rate and extent of starch digestion has been measured in vitro using a method developed by Englyst et al. ${ }^{(13-15)}$, which classifies starch into three major fractions: rapidly digestible starch (RDS), slowly digestible starch (SDS) and resistant starch.

Statistical analyses using regression models have been performed to explain the influence of starch digestibility in cereal products or other plant food products on $\mathrm{GI}^{(9,14,16,17)}$. The number of tested products and product categories in these studies was low ${ }^{(9,16)}$ and results are therefore difficult to extrapolate. The contribution of the physico-chemical characteristics of the food products was not extensively investigated. In addition to GI, insulinaemic index (II) is also investigated because of its role in glucose homeostasis and its regulating effects on lipid metabolism ${ }^{(18-21)}$.

The aim of the present work was thus to test the influence of $\mathrm{CHO}$ digestibility and the nutritional characteristics of a

Abbreviations: $\mathrm{CHO}$, carbohydrate; $C_{\max g}$, maximum concentration of blood glucose; $C_{\max }$, maximum concentration of blood insulin; $C_{\max }$, maximum concentration; GI, glycaemic index; iAUC, incremental AUC; iAUC ${ }_{g}$, incremental area under the blood glucose response curve; iAUC ${ }_{i}$, incremental area under the blood insulin response curve; II, insulinaemic index; PLS, partial least squares; RDS, rapidly digestible starch; SDS, slowly digestible starch; VIP, variable importance in projection; $\Delta_{\text {peak g, }} \Delta_{\text {peak }}$ of glycaemic response; $\Delta_{\text {peak }}, \Delta_{\text {peak }}$ of insulin response. 
large sample of different categories of cereal-based foods on GI, II and on various parameters of glycaemic and insulinaemic response curves; to evaluate the contribution of the interactions among the different parameters in cereal-based foods; to discuss the physiological relevance of glycaemic and insulinaemic descriptors.

\section{Materials and methods}

\section{Subjects and in vivo studies}

Since 1998, 190 cereal products have been tested according to the international standard methodology for $\mathrm{GI}^{(22,23)}$ using $50 \mathrm{~g}$ glucose dissolved in $250 \mathrm{ml}$ water as the reference food $(\mathrm{GI}=100)$ as proposed by Brouns et al. ${ }^{(24)}$. The procedures followed during the clinical studies were in accordance with the Declaration of Helsinki and the ethical standards of the responsible institutional or regional committees on human experimentation, and all the subjects gave informed written consent.

A total of 591 volunteers (in forty-nine trials) consumed the cereal products in test portions containing $50 \mathrm{~g}$ of glycaemic CHO with $250 \mathrm{ml}$ water within $10-15 \mathrm{~min}$. Capillary blood samples were collected at the consumption time (T0), and after $15,30,45,60,90$ and $120 \mathrm{~min}$ to build the glycaemic and insulinaemic response curves for each test product. As indicated in the International Standards (ISO 26642:2010) ${ }^{(23)}$, the subjects selected for the GI test were healthy human subjects of both sexes who complied with two additional inclusion criteria: fasting glycaemia $<6.1 \mathrm{~mm}$ and 2-h glycaemia following the ingestion of a $50-\mathrm{g}$ glucose solution $<8.9 \mathrm{~mm}$. Mean age and BMI of the study subjects were, respectively, 24.7 (SD 4.7) years and $22.3(\mathrm{SD} 1.9) \mathrm{kg} / \mathrm{m}^{2}$ Fasting glycaemia and 2-h glycaemia (mm) were, respectively, $5 \cdot 11$ (SD 0.40) and 4.62 (SD 0.72).

The GI of a given food reflects how much of its digestible $\mathrm{CHO}$ raise blood glucose levels. It is defined as the $\mathrm{iAUC}_{g}$ after consumption of a portion of test food providing $50 \mathrm{~g}$ of the available $\mathrm{CHO}$, expressed as a percentage of the average $\mathrm{iAUC}_{\mathrm{g}}$ to the same amount of $\mathrm{CHO}$ from a reference food (glucose) ingested by the same subject on a separate occasion. The $\mathrm{iAUC}_{\mathrm{g}}$ is the incremental area under the blood glucose response curve (calculated for $2 \mathrm{~h}$ following the ingestion of the tested product: $0-120 \mathrm{~min}$ ), ignoring the area beneath the fasting concentration. In the present work, the $\mathrm{iAUC}_{g}$ was calculated according to the trapezoidal method as recommended in the International Standard ${ }^{(23)}$. For an individual subject, the GI of a tested food is given by: AAUC $_{g}$ test food/ average $\mathrm{iAUC}_{\mathrm{g}}$ reference food $\times 100$. Other parameters defining the shape of the response curves over $2 \mathrm{~h}$ were also investigated: $\mathrm{iAUC}_{\mathrm{g}}, C_{\operatorname{maxg}}$ (maximum concentration of blood glucose) and $\Delta_{\text {peak g }}\left(\Delta_{\text {peak }}\right.$ of glycaemic response; difference between $C_{\max }$ and baseline concentration). Moreover, II was calculated similarly to GI in measuring the extent to which a food raises plasma insulin concentration ${ }^{(25)}$. The same parameters (incremental area under the blood insulin response curve $\left(\mathrm{iAUC}_{\mathrm{i}}\right)$, maximum concentration of blood insulin $\left(C_{\operatorname{maxi}}\right), \Delta_{\text {peak }}$ of insulin response $\left.\left(\Delta_{\text {peak }}\right)\right)$ as those of the glycaemic response curve were used to describe insulinaemic response.

\section{Product database with characteristics of the cereal products by category}

An internal database of 190 products representing a wide range of processed cereal products was used for the statistical analyses. These products were classified into four categories according to the manufacturing process: extruded cereals, dried bakery products and crackers, soft bakery products and biscuits. Nutritional composition and starch digestibility parameters in the cereal products used in this analysis are summarised in Table 1 . The nutritional parameters were analytically measured (fibres: AOAC 985-29; total starch: enzymatic method as described in the French standard V18-121; fat and moisture: methods described in the French Decree of 08/09/1977; proteins: Kjeldahl method). In vitro starch digestibility was assessed using the method developed by Englyst et $a l^{(26)}$. It involved several steps that simulate the in vivo enzymatic digestion of $\mathrm{CHO}$ in the stomach and the small intestine and the release of glucose at several experimental times. This method makes it possible to measure the amounts of different starch and sugar fractions according to their digestibility $^{(14,15)}$ (Fig. 1).

The starch fractions are defined as the RDS (the starch fraction digested in vitro within 20 min of hydrolysis), the SDS (the starch fraction digested in vitro in between 20 and $120 \mathrm{~min}$ of hydrolysis) and the resistant starch. The resistant starch fraction is calculated as the released glucose from further hydrolysis of the starch remaining in the main incubation tube at the end of $120 \mathrm{~min}$. The notion of rapidly available glucose has been proposed as being the amount of glucose likely to be available for rapid absorption in the human small intestine ${ }^{(15)}$. Regarding cereal products, slowly available glucose can be assimilated into SDS. We will therefore use the term SDS in the present paper.

\section{Statistical analyses}

For investigating the impact of cereal product characteristics on GI, II and glucose and insulin response parameters (iAUC, $\left.C_{\text {max }}, \Delta_{\text {peak }}\right)$, a step-by-step statistical analysis was applied using JMP Software version 10.0 (SAS Institute Inc.). Partial least squares (PLS) regression analysis was first performed to select the variables of product composition (among nutritional composition and starch digestibility parameters) that may impact on GI, II and each of the six metabolic response parameters. In this PLS regression analysis, eight individual variables were tested on the four glycaemic response parameters (GI, iAUC,$C_{\max g}$ and $\Delta_{\text {peak g }}$ ) as a first step: fat, dietary fibres, total available $\mathrm{CHO}$, proteins, fructose, free sugar glucose, RDS and SDS. Only parameters with a variable importance in projection (VIP) value greater than $0 \cdot 8$, indicative of their significant impact, were considered in the following steps. Another PLS regression analysis was then performed on the four glycaemic response parameters including the product variables selected in the first step and all the possible 
Table 1. Mean of nutritional composition and starch digestibility parameters ( $\mathrm{g} /$ portion size providing about $50 \mathrm{~g}$ available carbohydrates) of the $190 \mathrm{cereal}$ products classified by category (Mean values and standard deviations; median values and minimum and maximum values)

\begin{tabular}{|c|c|c|c|c|c|c|c|c|c|c|c|c|c|c|c|c|c|c|c|c|}
\hline & \multicolumn{4}{|c|}{ Extruded cereals } & \multicolumn{4}{|c|}{ Dried bakery products and crackers } & \multicolumn{4}{|c|}{ Soft bakery products } & \multicolumn{4}{|c|}{ Biscuits } & \multicolumn{4}{|c|}{ All } \\
\hline & Mean & SD & Median & $\begin{array}{l}\text { Minimum- } \\
\text { maximum }\end{array}$ & Mean & SD & Median & $\begin{array}{l}\text { Minimum- } \\
\text { maximum }\end{array}$ & Mean & SD & Median & $\begin{array}{l}\text { Minimum- } \\
\text { maximum }\end{array}$ & Mean & SD & Median & $\begin{array}{l}\text { Minimum- } \\
\text { maximum }\end{array}$ & Mean & SD & Median & $\begin{array}{l}\text { Minimum- } \\
\text { maximum }\end{array}$ \\
\hline $\begin{array}{l}\text { Number of } \\
\text { products }\end{array}$ & & & 23 & & & & 23 & & & & 9 & & & & 135 & & & & 190 & \\
\hline Portion size (g) & 63 & 6 & & & 69 & 5 & & & 92 & 9 & & & 72 & 69 & & & 71 & 8 & & \\
\hline \multicolumn{21}{|l|}{ Nutritional composition } \\
\hline Moisture (g) & 2.6 & 1.7 & $2 \cdot 1$ & $0.8-7.8$ & $1 \cdot 8$ & 0.7 & 1.6 & $0.9-3 \cdot 6$ & 19.4 & 7.1 & $20 \cdot 8$ & $2 \cdot 5-26 \cdot 0$ & $2 \cdot 3$ & $2 \cdot 2$ & 1.9 & $0 \cdot 6-14 \cdot 3$ & 3.1 & 4.5 & 1.9 & $0.6-26.0$ \\
\hline Energy (kcal) & 253 & 36 & 240 & $204-340$ & 281 & 26 & 282 & $218-332$ & 318 & 34 & 327 & $272-360$ & 305 & 28 & 312 & $239-439$ & 296 & 34 & 306 & $204-439$ \\
\hline Energy (kJ) & 1059 & 151 & 1005 & $854-1424$ & 1176 & 109 & 1181 & $913-1390$ & 1331 & 142 & 1369 & $1139-1507$ & 1277 & 117 & 1306 & $1001-1838$ & 1239 & 142 & 1281 & $854-1838$ \\
\hline Fat (g) & 4.8 & 3.7 & $4 \cdot 1$ & $0.5-13.9$ & 6.8 & 3.1 & 5.4 & $0.9-13.8$ & 11.1 & 2.8 & $12 \cdot 1$ & $6 \cdot 9-14 \cdot 0$ & $10 \cdot 3$ & 2.5 & 11.1 & $3.5-18 \cdot 1$ & $9 \cdot 3$ & 3.4 & $10 \cdot 4$ & $0.5-18.1$ \\
\hline Proteins (g) & $5 \cdot 1$ & 1.3 & 5.3 & $2 \cdot 8-8 \cdot 9$ & 7.7 & 1.6 & 7.8 & $5 \cdot 3-10 \cdot 9$ & $7 \cdot 2$ & $2 \cdot 7$ & $7 \cdot 2$ & $4 \cdot 1-12 \cdot 3$ & $5 \cdot 6$ & $2 \cdot 1$ & $5 \cdot 3$ & $2 \cdot 5-21 \cdot 6$ & $5 \cdot 8$ & $2 \cdot 1$ & 5.4 & $2.5-21.6$ \\
\hline Fibres (g) & 2.5 & $1 \cdot 2$ & $2 \cdot 3$ & $0.6-4.9$ & 5.7 & $3 \cdot 3$ & $5 \cdot 1$ & $1.8-11.1$ & 4.1 & 0.9 & 4.4 & $2 \cdot 6-4 \cdot 8$ & $4 \cdot 3$ & 3.5 & 3.6 & $1.1-30.1$ & $4 \cdot 3$ & 3.3 & 3.6 & $0.6-30.1$ \\
\hline $\begin{array}{l}\text { Glycaemic } \\
\mathrm{CHO}(\mathrm{g})\end{array}$ & 49.9 & 0.6 & $50 \cdot 0$ & $47 \cdot 5-50 \cdot 2$ & 49.9 & 0.6 & $50 \cdot 0$ & $47 \cdot 3-50 \cdot 0$ & 49.1 & $1 \cdot 1$ & $50 \cdot 0$ & $47 \cdot 5-50$ & 49.8 & $1 \cdot 2$ & $50 \cdot 0$ & $44 \cdot 1-53 \cdot 6$ & 49.8 & 1.1 & $50 \cdot 0$ & $44 \cdot 1-53 \cdot 6$ \\
\hline Glycaemic index & 67 & 13 & 63 & $51-94$ & 60 & 9 & 61 & $42-79$ & 58 & 8 & 59 & $46-70$ & 49 & 10 & 49 & $17-82$ & 53 & 12 & 52 & $17-94$ \\
\hline Insulinaemic index & 72 & 13 & 70 & $50-97$ & 66 & 13 & 63 & $46-106$ & 79 & 21 & 74 & $52-115$ & 62 & 15 & 61 & $10-102$ & 64 & 16 & 63 & $10-115$ \\
\hline \multicolumn{21}{|l|}{ Starch fractions } \\
\hline Total fructose (g) & 8.3 & 3.0 & $7 \cdot 0$ & $1.9-12.9$ & $2 \cdot 0$ & 1.4 & 1.5 & $0 \cdot 2-5 \cdot 1$ & 6.4 & 3.8 & 6.8 & $1.4-13.0$ & 8.6 & $2 \cdot 0$ & 8.3 & $0.0-15 \cdot 0$ & 7.6 & 3.1 & 8.0 & $0.0-15 \cdot 0$ \\
\hline $\begin{array}{l}\text { Free sugar } \\
\quad \text { glucose }(\mathrm{g})\end{array}$ & 9.1 & 3.9 & $7 \cdot 1$ & $2 \cdot 1-15 \cdot 7$ & 1.0 & 1.1 & 0.6 & $0.1-3 \cdot 6$ & 6.6 & 4.8 & 5.7 & $0.6-13.5$ & 8.8 & $2 \cdot 3$ & $8 \cdot 2$ & $3 \cdot 1-18.8$ & 7.7 & 3.6 & 7.8 & $0.1-18.8$ \\
\hline RAG (g) & 39.4 & $4 \cdot 1$ & 40.7 & $29 \cdot 3-46 \cdot 5$ & $42 \cdot 6$ & 2.5 & $42 \cdot 7$ & $37.4-46.0$ & 38.7 & $3 \cdot 3$ & 39.9 & $33 \cdot 4-42 \cdot 5$ & 29.6 & 3.3 & 29.2 & $21 \cdot 5-40.9$ & 32.7 & $6 \cdot 1$ & 30.5 & $21 \cdot 5-46 \cdot 5$ \\
\hline RDS (g) & 29.9 & 7.8 & 33.3 & $14 \cdot 5-44 \cdot 4$ & $41 \cdot 6$ & 3.1 & $41 \cdot 3$ & $34 \cdot 0-45 \cdot 5$ & 31.5 & 6.7 & 31.4 & $19 \cdot 9-40 \cdot 7$ & 20.8 & 3.9 & 20.4 & $12 \cdot 7-34.4$ & $24 \cdot 9$ & 8.5 & $22 \cdot 2$ & $12 \cdot 7-45 \cdot 5$ \\
\hline SDS (g) & 0.9 & 0.8 & 0.6 & $0 \cdot 1-2 \cdot 8$ & $3 \cdot 3$ & 1.9 & 3.1 & $0.1-7.5$ & 3.2 & $1 \cdot 0$ & 3.4 & $1 \cdot 8-4.7$ & 10.9 & $3 \cdot 2$ & 11.5 & $0.8-17.8$ & 8.5 & 4.8 & 9.8 & $0.1-17.8$ \\
\hline RS (g) & 0.8 & 0.4 & 0.7 & $0.4-1 \cdot 8$ & 1.6 & 0.7 & 1.5 & $0.1-2 \cdot 7$ & $1 \cdot 3$ & 0.4 & 1.4 & $0.7-1.7$ & 0.9 & 0.4 & 0.8 & $0.2-2 \cdot 7$ & $1 \cdot 0$ & 0.5 & 0.9 & $0.1-2 \cdot 7$ \\
\hline
\end{tabular}

$\mathrm{CHO}$, carbohydrate; RAG, rapidly available glucose; RDS, rapidly digestible starch; SDS, slowly digestible starch; RS, resistant starch. 


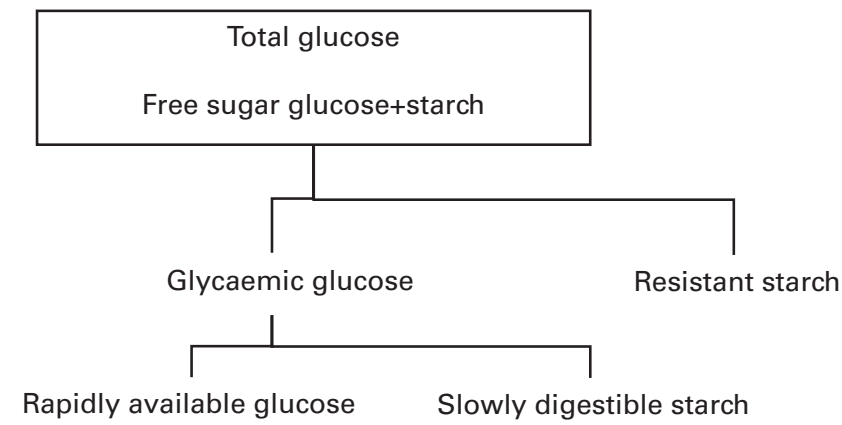

Fig. 1. Sugar and starch components and their successive digestible fractions as determined by the Englyst method ${ }^{(26)}$.

interactions between them, including the quadratic terms of the variables. These terms are representative of a non-linear effect between product variables and glycaemic response. As for the first step, only interactions with a VIP value greater than 0.8 were considered. Finally, product parameters and their interactions with a contribution to the model greater than $5 \%$ were kept in the final model. In the case of interactions selected for the models, all the parameters involved in the interactions were also kept. Once selected, these product variables were introduced into a new PLS analysis integrating the four glycaemic response parameters. The prediction formulas of this model for each glycaemic response parameter were extracted and a linear regression analysis was done between the actual value of each glycaemic response parameter and its predicted value to obtain a $R^{2}$ value for each parameter with this model. A prediction profiler was also built on Excel Software version 10.0 (Microsoft Corporation) using the prediction formula obtained from the model developed for glycaemic responses. It was used to understand and illustrate the impact of the product variables and their interactions on metabolic response parameters.

The same PLS methodology was followed for the insulinemic response parameters. However, it is known that plasma insulin tests are not standardised and that the use of different analytical kits can significantly impact the analytical results $^{(27,28)}$. We also investigated whether the type of analytical kit used in the laboratories could impact the results on II, $\mathrm{iAUC}_{\mathrm{i}}, C_{\max \mathrm{i}}$ and $\Delta_{\text {peak } \mathrm{i}}$. This was done by using an ANOVA on the $\mathrm{iAUC}_{\mathrm{i}}$ obtained after the consumption of the reference product (glucose).

\section{Results}

\section{Characteristics of the cereal products}

All values are expressed as means with standard deviations and as median, minimum and maximum. Nutritional characteristics in cereal products are shown per portion of product providing $50 \mathrm{~g}$ of available $\mathrm{CHO}$ (Table 1). The biscuit category had the lowest average value of GI (49 (SD 10)) and II (62 (SD 15)), while the extruded cereal category had the highest GI value (67 (SD 13)). The highest II was observed in the soft bakery products (79 (SD 21)). Dried bakery products and crackers had the highest rapidly available glucose content and biscuits the lowest (42.6 (SD 2.5) v. 29.6 (SD 3.3) g, per $50 \mathrm{~g}$ available $\mathrm{CHO}$ ). The biscuits had the highest SDS content $(10 \cdot 8$ (sD 3.2) g, per $50 \mathrm{~g}$ available $\mathrm{CHO})$.

\section{Selection of the nutritional composition and starch digestibility parameters impacting the glycaemic response}

All the analyses were performed on the full range of product characteristics present in the database. The variables of nutritional composition (fat, proteins, total available $\mathrm{CHO}$, dietary fibres) and starch digestibility (fructose, free sugar glucose, RDS, SDS) were integrated into the PLS analysis testing the four parameters of glycaemic response: $\mathrm{GI}, \mathrm{iAUC}_{\mathrm{g}}, C_{\operatorname{maxg}}$ and $\Delta_{\text {peak g. }}$ All the analyses were performed on the whole range of product characteristics in the database. Testing these four parameters at the same time showed that their changes were very similar and thus strengthened our analysis. From this first step, SDS, fat, dietary fibres and RDS displayed a VIP value greater than 0.8 and were kept in the second step of the PLS analysis. In this second step, we also introduced all the interactions among these four variables. These four variables (fat, fibres, RDS and SDS) and seven interactions (fibres ${ }^{2}$, $\mathrm{fat}^{2}, \mathrm{SDS}^{2}$, fat $\times$ SDS, fat $\times$ fibres, SDS $\times$ RDS and fat $\times$ RDS) displayed a VIP $>0 \cdot 8$. A final step consisted of selecting variables and interactions contributing for more than $5 \%$ in the model. Therefore, the final model included four variables (SDS, fat, fibres and RDS) and four interactions (fibres ${ }^{2}$, SDS $\times$ RDS, fat $\times$ fibres and $\mathrm{fat}^{2}$ ). Here, the main contributors to the model built over the full range of the biscuits characteristics were SDS, fibres ${ }^{2}$ and fat with contributions of $17 \cdot 4,15 \cdot 9$ and $13.7 \%$, respectively (Table 2 ). 
Table 2. Factors significantly influencing glycaemic response (glycaemic index, incremental area under the blood glucose response curve, $\Delta_{\text {peak }}$ of glycaemic response and maximum concentration of blood glucose)

\begin{tabular}{lc}
\hline Selected variables & Impact $(\%)$ \\
\hline SDS & 17.4 \\
Fibres $^{2}$ & 15.9 \\
Fat & 13.7 \\
SDS $\times$ RDS & 10.5 \\
Fat $\times$ fibres & 9.5 \\
Fat $^{2}$ & 6.8 \\
RDS & $5 \cdot 5$ \\
Fibres $^{*}$ & 4.8 \\
\hline
\end{tabular}

SDS, slowly digestible starch; RDS, rapidly digestible starch.

${ }^{*}$ Kept as this variable is involved in interactions.

The same PLS approach was followed to select the product variables impacting the insulinaemic response parameters. The analysis indicated that SDS, fat, fibres and proteins are the characteristics of the cereal products that influence II and the insulin response parameters (iAUC $C_{\mathrm{i}}, C_{\max \mathrm{i}}$ and $\Delta_{\text {peak i }}$ ) the most. When integrating the interactions between these components in the PLS analysis, the best model was the one including four variables (fat, fibres, proteins and SDS) and six interactions (fibres ${ }^{2}$, fibres $\times$ fat, fat $\times$ SDS, fat $^{2}$, fibres $\times$ proteins and SDS $^{2}$ ). When selecting only variables contributing for more than $5 \%$ in the model, three variables (SDS, fibres and fat) and five interactions (fat $\times$ fibres, fibres ${ }^{2}$, fat $\times$ SDS, $\operatorname{SDS}^{2}$ and $\mathrm{fat}^{2}$ ) were included in the final model (Table 3).

\section{Relationships between glycaemic response parameters and product characteristics}

Almost half (48.9\%) of the glycaemic response was explained by the model including conjointly the four selected variables and the four interactions tested. In this model, the components SDS and fat impacted the glycaemic response the most. Fibres $^{2}$, SDS $\times$ RDS and fat $\times$ fibres interactions also had an important influence on the glycaemic response. The regression analysis performed to determine the individual contributions of the selected variables to the glycaemic parameters over the full range of biscuits indicated that the variables explained $52 \cdot 9,41 \cdot 4,41 \cdot 2$ and $60 \cdot 1 \%$ of the variance in GI, iAUC,$C_{\operatorname{maxg}}$ and $\Delta_{\text {peak g }}$, respectively (all $P<0.0001$ ). The GI and $\Delta_{\text {peak g }}$ are the glycaemic response parameters that are best explained by the model.

Contour plots for modelised GI clusterised on three levels of SDS content (Fig. 2(a)) indicated that for identical contents of fat and fibres in products, GI is higher with low SDS products (range 80-50). With low and medium SDS contents in the cereal products, increased fat and fibres lowers the GI value (from 80 to 40 and from 70 to 20 , respectively), indicating that fat and fibres make important contributions to GI. With high SDS content ( $>13 \mathrm{~g}$ /portion), the contributions of fibres and fat to GI are limited (the GI values do not fluctuate much, ranging from 40 to 60 ). A similar profile of contour plot for $\Delta_{\text {peak g }}$ was obtained, indicating the same influence of the product characteristics on $\Delta_{\text {peak g. }}$.

To further understand the effect of the fibres $\times$ fat interaction on GI, another approach was used. It consisted in profiling the effect of fibre content on GI at the medium SDS level $(8.5 \mathrm{~g} /$ portion) and for three levels of fat: $0.5,9.3$ and $18 \cdot 1 \mathrm{~g} /$ portion (corresponding to minimum, medium and maximum fat contents observed in the product database) (Fig. 3). The graph shows that GI decreases when the fibre content of the product portion increases. This effect is reduced as the fat content increases until being lost with the highest fat content.

\section{Relationships between insulinaemic response parameters and product characteristics}

The model developed for insulinaemic response parameters including the three product variables (fat, fibres and SDS) and the five interactions (fibres ${ }^{2}, \mathrm{fat}^{2}, \mathrm{SDS}^{2}$, fat $\times$ fibres and fat $\times$ SDS) explains $43.3 \%$ of the four insulinaemic descriptors considered together. When testing the kit effect, the ANOVA indicated that the type of kit used for insulin quantification significantly impacted the results $(P<0 \cdot 0001)$. Therefore, we did not further analyse the insulin parameters as the observed kit effect biases the results.

\section{Discussion}

This is the first study that evaluated the effect of starch fraction and macronutrient contents on the metabolic responses of an important dataset (190 cereal products). The present results, based on various categories of cereal products, indicate that $53 \%$ of GI variability is explained by a model involving both parameters of starch digestibility (SDS and RDS) and nutritional composition (fat and fibres). We found that SDS was the main parameter influencing glycaemic response, accounting for $17.4 \%$ in its variance, while RDS explained only $5.5 \%$ of the variance. In previous studies, rapidly available glucose was highly correlated to GI and glycaemic response ${ }^{(14,15)}$. Moreover, it has been reported both on twenty-three cereal products of different categories (cereals, bakery products, crackers and biscuits) ${ }^{(9)}$ and on twenty-four plain sweet biscuits $^{(16)}$ that SDS was the major contributing factor to

Table 3. Factors significantly influencing insulin response (insulinaemic index, incremental area under the blood insulin response curve, $\Delta_{\text {peak }}$ of insulin response and maximum concentration of blood insulin)

\begin{tabular}{lc}
\hline Selected variables & Impact (\%) \\
\hline Fat $\times$ fibres & 18.7 \\
SDS & 14.9 \\
Fibres & \\
Fat $\times$ SDS & 11.0 \\
SDS $^{2}$ & 9.4 \\
Fat $^{2}$ & 8.9 \\
Fibres $_{\text {Fat }}^{*}$ & 8.7 \\
\hline
\end{tabular}

SDS, slowly digestible starch.

${ }^{*}$ Kept as this variable is involved in interactions. 

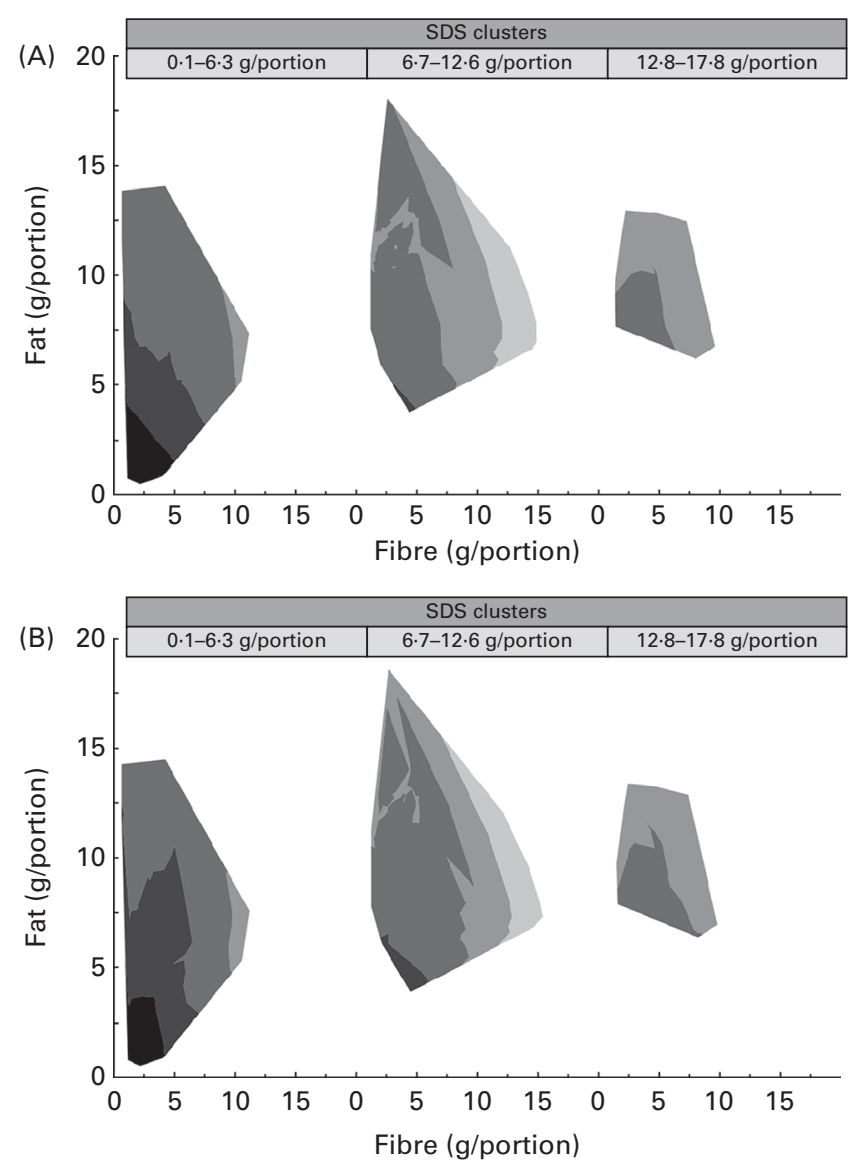

Fig. 2. Impact of fat and fibres on (a) glycaemic index (GI) and (b) $\Delta_{\text {peak }}$ of glycaemic response $\left(\Delta_{\text {peakg }}\right)$ values clusterised as low, medium and high levels of slowly digestible starch ( $\mathrm{g} /$ portion) in the cereal products.

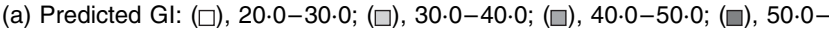

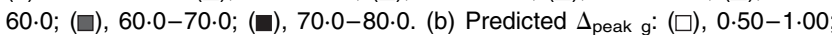
( $\square), \quad 1.00-1.50 ;(\square), 1.50-2.00 ;(\square), 2.00-2.50 ;(\square), 2.50-3.00 ;(\square)$, $3.00-3.50$

GI variation. The results of the present study, obtained on a larger dataset of 190 cereal products, confirm these previous observations

Moreover, in this statistical analysis, we showed a $13.7 \%$ contribution of fat in the glycaemic response. Fat content has already been shown to influence the glycaemic response in several studies ${ }^{(9,16,29,30)}$. In thirteen European meals, Flint et $a l .{ }^{(30)}$ showed that GI was more strongly correlated with either fat, protein or total energy content than with CHO content alone. As noted by the authors, available $\mathrm{CHO}$ are fixed to $50 \mathrm{~g}$ and fat and proteins vary; therefore, it is not surprising that the best prediction model included both fat and protein contents of the test meals, which are directly related to increased energy. The $\mathrm{CHO}$ content in the present study was also fixed at $50 \mathrm{~g}$ of available $\mathrm{CHO}$, but protein and fat contents in the cereal products were below the ranges of the meals used by Flint et al. ${ }^{(30)}: 2-22 \mathrm{~g}$ for protein and $0.5-18 \mathrm{~g}$ for fat in the present study, $v$. respectively 5-28 and $3-42 \mathrm{~g}$ in the test meals in the study of Flint et al. ${ }^{(30)}$. This may explain why no impact of proteins on the glycaemic response was found in the present study. Another possible explanation could be that the meals were composed of various foods leading to more intricate interactions than with cereal products tested alone. The quality of lipids and proteins contained in the products was not investigated in the present study. However, many studies have evaluated these parameters on postprandial glycaemic and insulinaemic responses in both healthy subjects and patients with type 2 diabetes. The main effect of lipid quality seems to be on exacerbated insulin response ${ }^{(31,32)}$. However, similar effect was not confirmed by more recent work ${ }^{(33-35)}$. Regarding the quality of proteins, several studies have investigated the impact of proteins from different sources on glycaemia and insulinaemia $^{(36)}$. Insulinotropic effect of proteins was related specifically to animal proteins such as whey proteins, due to their high content of branched-chain amino acids. However, literature review did not allow reaching a consensus on the impact of proteins on glycaemic and insulinaemic responses.

We also showed that fibre contributes to glycaemic response and is especially relevant within the interactions included in the model. Other previous studies that tested the impact of dietary fibres have shown that they do influence the $\mathrm{GI}^{(37,38)}$. The importance of fat and fibre contents, alone or in combination, in glycaemic response may be explained by physiological mechanisms. Interactions of starch with fibre and other food components can prevent effective diffusion and adsorption of the $\alpha$-amylase into the substrate ${ }^{(12,39)}$. However, management of blood glucose levels may be achieved through means other than the ones influencing the susceptibility of starch to digestion. The ingredients present within the food matrix may influence the glucose metabolism through regulation of gastric emptying, gut hormone profile and glucose absorption ${ }^{(12)}$. Soluble fibres can reduce the rate of gastric emptying by increasing the digestate in the upper part of the gastrointestinal tract. However, the viscosity properties of fibres seem to be more important in regulating the glycaemic response than the fibre quantity ${ }^{(40)}$. SDS has

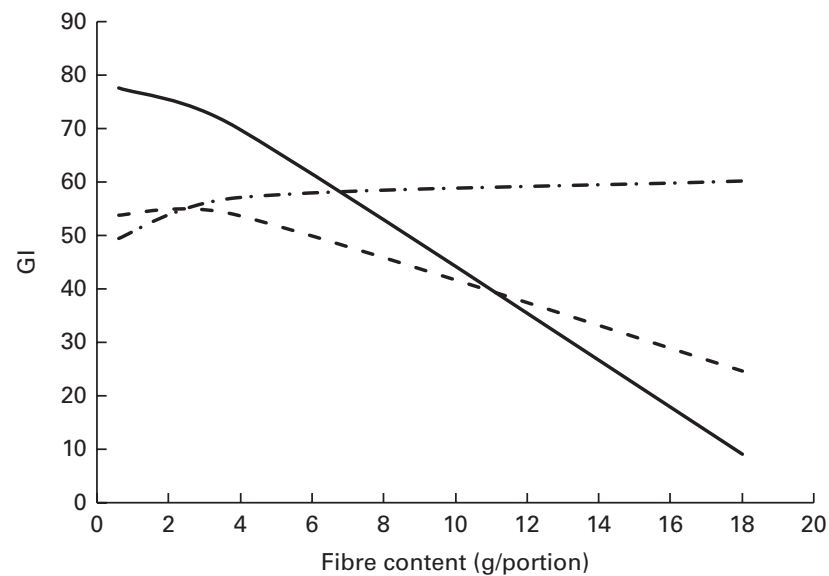

Fig. 3. Example of prediction profiler showing the fibre content effect on glycaemic index (GI) at different fat levels at a medium level of slowly digestible starch. Ordinates correspond to the predicted GI values. Fat levels correspond to minimum $(0.5 \mathrm{~g} /$ portion), medium ( $9.3 \mathrm{~g} /$ portion) and maximum $(18.1 \mathrm{~g} /$ portion) fat contents of products present in the database. _, $0.5 \mathrm{~g}$ of fat/portion; -..., 9.3 g of fat/portion; -.-, 18.1 g of fat/portion. 
previously been shown to reduce the glycaemic response by decreasing the glucose appearance rate in blood circulation $^{(41,42)}$. Fat may also reduce postprandial glycaemia by slowing down gastric emptying ${ }^{(43)}$. Normand et al. ${ }^{(29)}$ found that while medium fat addition ( $15 \mathrm{~g}$ ) to starch decreases the initial glycaemic peak, the addition of a larger amount of fat $(45 \mathrm{~g})$ to starch appears to be unfavourable to glycaemic response by leading to a feature of insulin resistance.

The originality of the present study was to bring out the contribution of interactions between components in the glycaemic response. The interactions of fibres ${ }^{2}, \mathrm{SDS} \times \mathrm{RDS}$, fat $\times$ fibres and fat $^{2}$ accounted for $15.9,10.5,9.5$ and $6.8 \%$, respectively, to the glycaemic response. The importance of these interactions has been highlighted by the present results, showing that not only the SDS level but also the fat and fibre contents impact glycaemic response. We also showed with our food database that fat and fibre contents have an impact on GI for low and medium SDS levels, but this effect is not observed when the SDS level is high. In addition, fat interacts with fibres to minimise the effect of fibre on glycaemic response. The present results show that the relative macronutrient contents modulate the glycaemic response differently.

The limitation of the present study is that it focused on processed cereal products only, which have defined ranges of macronutrient contents. Our database is not composed of equal amounts of information for each category, with a higher sample of products being rotary moulded biscuits. However, this database can be considered as representative of marketed sweet cereal products. In addition, the recipes of these tested cereal foods make it possible to estimate the role of each macronutrient within the context of a complex food matrix.

In a database including 1126 food products from all categories, Brand-Miller et al. ${ }^{(44)}$ showed that GI was correlated to some attributes of the glycaemic response, including the absolute peak response. The present results are in accordance with this and suggest that not only GI but also the $\Delta_{\text {peak }}$ of the glycaemic curve can be explained by the product characteristics for cereal products. Indeed, the GI does not take into account the shape of the glycaemic response curve and its measurement is obtained, thanks to the 2-h postprandial response. To take the shape of the curve into account, Rosen et al. ${ }^{(45)}$ propose measuring the glycaemic profile ( $\mathrm{min} / \mathrm{mm})$ of the products to evaluate the course of postmeal glycaemia. The glycaemic profile is defined as the time (min) during which the blood glucose is above fasting concentration (3-h postprandial glucose evaluation) divided by the blood glucose $\Delta_{\text {peak }}$ value (mm) for each subject and test meal $^{(45)}$. The present results indicate that the $\Delta_{\text {peak }}$, which takes into account the magnitude of the glycaemic response, may bring added value to GI to describe the glycaemic response. It would be of public health interest to take into account, in addition to the GI, the magnitude of the glycaemic response by investigating the $\Delta_{\text {peak }}$ as a high $\Delta_{\text {peak }}$ leads to greater insulin stimulation, which may induce deleterious effects in the diabetes genesis ${ }^{(46)}$
This is also the reason why we investigated the insulin response in addition to the glycaemic response. However, as noted by others, we found that the type of kit used for the insulin analyses significantly impacted the results, and we emphasise the need to standardise the kits for insulin detection analysis to confirm that the lower glycaemic responses obtained are not followed by an excessively high insulin response ${ }^{(27,28)}$.

Finally, the high contribution of some cereal product characteristics (SDS, fat and fibres) and their inter-dependance in the GI and glycaemic response parameters, such as $\Delta_{\text {peak g, }}$, contends for focusing on both the optimisation of the formula and the manufacturing process of cereal products to decrease postprandial glycaemic response. Reducing glycaemic response has been recognised as relevant to the prevention of metabolic diseases ${ }^{(1,7,47)}$.

\section{Acknowledgements}

We are grateful to Klaus Englyst (Englyst CarbohydratesResearch \& Services Limited, Southampton, UK) for his collaboration in determining the $\mathrm{CHO}$ digestibility profile of the cereal products; Jennie Brand-Miller (Sydney University, Australia) for her advices related to GI tests.

The work described in this article was sponsored by Mondelez France R\&D SAS (6 Rue René Razel - Bâtiment K, 91400 Saclay, France).

A. M., A. G. and S. V. are employees of the Nutrition Department, Mondelez International R\&D; O. B. is owner of Statistique Industrielle KHI2 Consulting (KSIC), Esches, France; F. A. is an employee of the Human Nutrition Unit of the University of Sydney.

The authors' responsibilities are as follows: A. M., A. G. and S. V. designed the research (project conception, development of overall research plan, and study oversight); F. A. was in charge of the GI tests; A. M., A. G. and S. V. discussed the results and planned the manuscript; O. B. and A. M. performed the statistical analyses. A. M., A. G., F. A., O. B. and S. V. edited and approved the final manuscript.

A. M., A. G. and S. V. are employees of Mondelez France R\&D SAS. O. B. received payment from Mondelez France R\&D SAS for performing the statistical analyses. O. B. and F. A. declare that they have no known conflicts of interest.

\section{References}

1. Blaak EE, Antoine JM, Benton D, et al. (2012) Impact of postprandial glycaemia on health and prevention of disease. Obes Rev 13, 923-984.

2. Wahlqvist ML, Wilmshurst EG \& Richardson EN (1978) The effect of chain length on glucose absorption and the related metabolic response. Am J Clin Nutr 31, 1998-2001.

3. Jenkins DJ, Wolever TM, Taylor RH, et al. (1981) Glycemic index of foods: a physiological basis for carbohydrate exchange. Am J Clin Nutr 34, 362-366.

4. Brand-Miller J, Hayne S, Petocz P, et al. (2003) Low-glycemic index diets in the management of diabetes: a meta-analysis of randomized controlled trials. Diabetes Care 26, 2261-2267. 
5. Frost G, Leeds A, Trew G, et al. (1998) Insulin sensitivity in women at risk of coronary heart disease and the effect of a low glycemic diet. Metab Clin Exp 47, 1245-1251.

6. Rizkalla SW, Taghrid L, Laromiguiere M, et al. (2004) Improved plasma glucose control, whole-body glucose utilization, and lipid profile on a low-glycemic index diet in type 2 diabetic men: a randomized controlled trial. Diabetes Care 27, 1866-1872.

7. Barclay AW, Petocz P, McMillan-Price J, et al. (2008) Glycemic index, glycemic load, and chronic disease risk a meta-analysis of observational studies. Am J Clin Nutr 87, 627-637.

8. Foster-Powell K, Holt SHA \& Brand-Miller JC (2002) International table of glycemic index and glycemic load values: 2002. Am J Clin Nutr 76, 5-56.

9. Englyst KN, Vinoy S, Englyst HN, et al. (2003) Glycaemic index of cereal products explained by their content of rapidly and slowly available glucose. Br J Nutr 89, 329-340.

10. Liljeberg H, Granfeldt Y \& Bjorck I (1992) Metabolic responses to starch in bread containing intact kernels versus milled flour. Eur J Clin Nutr 46, 561-575.

11. Granfeldt Y, Hagander B \& Bjorck I (1995) Metabolic responses to starch in oat and wheat products. On the importance of food structure, incomplete gelatinization or presence of viscous dietary fibre. Eur J Clin Nutr 49, 189-199.

12. Lehmann U \& Robin F (2007) Slowly digestible starch - its structure and health implications: a review. Trends Food Sci Technol 18, 346-355.

13. Englyst HN, Kingman SM \& Cummings JH (1992) Classification and measurement of nutritionally important starch fractions. Eur J Clin Nutr 46, Suppl. 2, S33-S50.

14. Englyst HN, Veenstra J \& Hudson GJ (1996) Measurement of rapidly available glucose (RAG) in plant foods: a potential in vitro predictor of the glycaemic response. Br J Nutr 75, 327-337.

15. Englyst KN, Englyst HN, Hudson GJ, et al. (1999) Rapidly available glucose in foods: an in vitro measurement that reflects the glycemic response. Am J Clin Nutr 69 448-454.

16. Garsetti M, Vinoy S, Lang V, et al. (2005) The glycemic and insulinemic index of plain sweet biscuits: relationships to in vitro starch digestibility. J Am Coll Nutr 24, 441-447.

17. Kai LE, Shujun W, Copeland L, et al. (2014) Discovery of a low-glycaemic index potato and relationship with starch digestion in vitro. Br J Nutr 111, 699-705.

18. Miller JB, Pang E \& Broomhead L (1995) The glycaemic index of foods containing sugars: comparison of foods with naturally-occurring $v$. added sugars. $\mathrm{Br} J$ Nutr 73, 613-623.

19. Holt SHA, Brand Miller JC \& Petocz P (1997) An insulin index of foods: the insulin demand generated by $1000-\mathrm{kJ}$ portions of common foods. Am J Clin Nutr 66, 1264-1276.

20. Lee BM \& Wolever TM (1998) Effect of glucose, sucrose and fructose on plasma glucose and insulin responses in normal humans: comparison with white bread. Eur J Clin Nutr 52, 924-928.

21. Saltiel AR \& Kahn CR (2001) Insulin signalling and the regulation of glucose and lipid metabolism. Nature $\mathbf{4 1 4}$ 799-806

22. WHO (1998) Carbohydrates in human nutrition. Report of a Joint FAO/WHO Expert Consultation, Rome, 14-18 April, 1997

23. ISO 26642:2010 (2010) Food Products - Determination of the Glycaemic Index (GI) and Recommendation for Food Classification, 18p. London: ISO.
24. Brouns F, Bjorck I, Frayn KN, et al. (2005) Glycaemic index methodology. Nutr Res Rev 18, 145-171.

25. Wolever TM, Jenkins DJ, Jenkins AL, et al. (1991) The glycemic index: methodology and clinical implications. Am J Clin Nutr 54, 846-854.

26. Englyst HN, Kingman SM, Hudson GJ, et al. (1996) Measurement of resistant starch in vitro and in vivo. Br J Nutr $\mathbf{7 5}$, 749-755.

27. Miller WG, Thienpont LM, Van Uytfanghe K, et al. (2009) Toward standardization of insulin immunoassays. Clin Chem 55, 1011-1018

28. Manley SE, Luzio SD, Stratton IM, et al. (2008) Preanalytical, analytical, and computational factors affect homeostasis model assessment estimates. Diabetes Care 31, $1877-1883$.

29. Normand S, Khalfallah Y, Louche-Pelissier C, et al. (2001) Influence of dietary fat on postprandial glucose metabolism (exogenous and endogenous) using intrinsically (13)Cenriched durum wheat. Br J Nutr 86, 3-11.

30. Flint A, Moller BK, Raben A, et al. (2004) The use of glycaemic index tables to predict glycaemic index of composite breakfast meals. Br J Nutr 91, 979-989.

31. Lardinois CK, Starich GH, Mazzaferri EL, et al. (1988) Effect of source of dietary fats on serum glucose, insulin, and gastric inhibitory polypeptide responses to mixed test meals in subjects with non-insulin dependent diabetes mellitus. J Am Coll Nutr 7, 129-136.

32. Rasmussen O, Lauszus FF, Christiansen C, et al. (1996) Differential effects of saturated and monounsaturated fat on blood glucose and insulin responses in subjects with non-insulin-dependent diabetes mellitus. Am J Clin Nutr 63, 249-253.

33. Thomsen C, Storm H, Holst JJ, et al. (2003) Differential effects of saturated and monounsaturated fats on postprandial lipemia and glucagon-like peptide 1 responses in patients with type 2 diabetes. Am J Clin Nutr 77, 605-611.

34. Burdge GC, Powell J \& Calder PC (2006) Lack of effect of meal fatty acid composition on postprandial lipid, glucose and insulin responses in men and women aged 50-65 years consuming their habitual diets. Br J Nutr 96, 489-500.

35. Shah M, Adams-Huet B, Brinkley L, et al. (2007) Lipid, glycemic, and insulin responses to meals rich in saturated, cis-monounsaturated, and polyunsaturated ( $n-3$ and $n-6)$ fatty acids in subjects with type 2 diabetes. Diabetes Care 30, 2993-2998.

36. Esteves de Oliveira FC, Pinheiro Volp AC \& Alfenas RC (2011) Impact of different protein sources in the glycemic and insulinemic responses. Nutr Hosp 26, 669-676.

37. Bjorck I \& Elmstahl HL (2003) The glycaemic index: importance of dietary fibre and other food properties. Proc Nutr Soc 62, 201-206.

38. Tosh SM (2013) Review of human studies investigating the post-prandial blood-glucose lowering ability of oat and barley food products. Eur J Clin Nutr 67, 310-317.

39. Colonna P, Leloup V \& Buleon A (1992) Limiting factors of starch hydrolysis. Eur J Clin Nutr 46, Suppl. 2, S17-S32.

40. Juntunen KS, Niskanen LK, Liukkonen KH, et al. (2002) Postprandial glucose, insulin, and incretin responses to grain products in healthy subjects. Am J Clin Nutr 75, 254-262.

41. Nazare JA, Rougemont Ad, Normand S, et al. (2010) Effect of postprandial modulation of glucose availability: short- and long-term analysis. Br J Nutr 103, 1461-1470. 
42. Vinoy S, Normand S, Meynier A, et al. (2013) Cereal processing influences postprandial glucose metabolism as well as the GI effect. J Am Coll Nutr 32, 79-91.

43. Cecil JE, Francis J \& Read NW (1999) Comparison of the effects of a high-fat and high-carbohydrate soup delivered orally and intragastrically on gastric emptying, appetite, and eating behaviour. Physiol Behav 67, 299-306.

44. Brand-Miller JC, Stockmann K, Atkinson F, et al. (2009) Glycemic index, postprandial glycemia, and the shape of the curve in healthy subjects: analysis of a database of more than 1000 foods. Am J Clin Nutr 89, 97-105.
45. Rosen LAH, Silva LOB, Andersson UK, et al. (2009) Endosperm and whole grain rye breads are characterized by low post-prandial insulin response and a beneficial blood glucose profile. Nutr J 8, 42.

46. Ceriello A, Colagiuri S, Gerich J, et al. (2008) Guideline for management of postmeal glucose. Nutr Metab Cardiovasc Dis 18, S17-S33.

47. Livesey G, Taylor R, Hulshof T, et al. (2008) Glycemic response and health - a systematic review and metaanalysis: relations between dietary glycemic properties and health outcomes. Am J Clin Nutr 87, 258S-268S. 